\title{
KETERBAGIAN TAK HINGGA DISTRIBUSI LOG-GAMMA DAN APLIKASINYA DALAM PEMBUKTIAN RUMUS PERKALIAN GAUSS DAN RUMUS LEGENDRE
}

\author{
MISHBAH ULHUSNA \\ Program Studi Magister Matematika, \\ Fakultas Matematika dan Ilmu Pengetahuan Alam, Universitas Andalas, \\ Kampus UNAND Limau Manis Padang, Indonesia, \\ ulhusna_82@yahoo.com
}

\begin{abstract}
Abstrak. Jika diberikan suatu peubah acak $Y=\alpha \log X$, dimana $X$ adalah peubah acak berdistribusi Gamma, $\alpha \in \mathbb{R}$ dan $Y$ adalah peubah acak berdistribusi Log-Gamma, maka dengan menggunakan representasi kanonik fungsi karakteristik dapat ditentukan ukuran Levy untuk distribusi Log-Gamma yang merupakan distribusi terbagi tak hingga. Representasi kanoniknya dapat digunakan untuk membuktikan rumus perkalian Gauss dan rumus Legendre.
\end{abstract}

Kata Kunci: Fungsi karakteristik, distribusi terbagi tak hingga, rumus perkalian Gauss, rumus Legendre

\section{Pendahuluan}

Konsep distribusi terbagi tak hingga merupakan kajian penting dalam teori peluang pada beberapa dekade terakhir, terutama dalam topik ukuran Levy untuk suatu fungsi karakteristik. Pembentukan distribusi terbagi tak hingga berdasarkan ukuran Levy dilakukan dengan menggunakan representasi kanonik dari suatu fungsi karakteristik distribusi tertentu. Ide dasar tentang distribusi terbagi tak hingga dalam permasalahan Teorema Limit Pusat adalah keterbagian peubah acak $X$ menjadi peubah-peubah acak yang saling bebas dengan distribusi yang sama. Peubah acak $X$ dikatakan terbagi menjadi $n$ jika terdapat peubah-peubah acak yang identik dan saling bebas $X_{1}, X_{2}, \cdots, X_{n}$ sedemikian sehingga $X=X_{1}+X_{2}+\cdots+X_{n}$. Suatu fungsi distribusi $F$ dikatakan terbagi tak hingga jika untuk setiap bilangan bulat positif $n$ terdapat suatu fungsi distribusi $F_{n}$ sedemikian sehingga $F$ adalah konvolusi $n$ kali dari $F_{n}$ dengan dirinya sendiri, yaitu $F=F_{n} * \cdots * F_{n}$ ( $n$ kali) [2].

Definisi yang ekuivalen dengan definisi distribusi terbagi tak hingga di atas adalah bahwa suatu fungsi distribusi $F$ dengan fungsi karakteristik $\varphi$ adalah terbagi tak hingga jika untuk setiap bilangan bulat positif $n$ terdapat fungsi karakteristik $\varphi_{n}$ sedemikian sehingga $\varphi(u)=\left(\varphi_{n}(u)\right)^{n}$ untuk setiap $u \in \mathbb{R}[2]$. Jika ditentukan suatu distribusi dari suatu peubah acak $Y=\alpha \log X$ dimana $X$ adalah peubah acak berdistribusi Gamma dan $\alpha \in \mathbb{R}$, maka dapat dikaji bentuk distribusi terbagi tak hingga dari peubah acak $Y$ serta bentuk representasi kanonik fungsi karakteristiknya. 
Pada paper ini akan dikaji tentang distribusi terbagi tak hingga dari peubah acak $Y=\alpha \log X$, dimana $X$ adalah peubah acak berdistribusi Gamma, $\alpha \in \mathbb{R}$ (untuk selanjutnya $Y$ disebut peubah acak berdistribusi Log-Gamma) dan bentuk representasi kanonik fungsi karakteristik dari peubah acak $Y$ tersebut serta aplikasinya terhadap pembuktian rumus perkalian Gauss dan rumus Legendre.

\section{Distribusi Gamma dan Distribusi Log-Gamma}

Berikut diberikan definisi fungsi kepadatan peluang, fungsi karakteristik dan bentuk kanonik dari fungsi karakteristik terbagi tak hingga dari distribusi Gamma.

Definisi 2.1. [2] Misalkan $X$ adalah peubah acak berdistribusi Gamma ( $X \sim$ $\operatorname{Gamma}(\xi, \beta))$. Fungsi kepekatan peluang $X$ didefinisikan sebagai

$$
f(x)=\frac{\beta^{\xi}}{\Gamma(\xi)} x^{\xi-1} e^{-\beta x} ; \quad x>0, \xi>0, \beta>0,
$$

dengan $\int_{0}^{\infty} x^{\xi-1} e^{-\beta x} d x=\frac{\Gamma(\xi)}{\beta^{\xi}}$. Kemudian

$$
\int_{-\infty}^{\infty} f(x) d x=\int_{-\infty}^{\infty} \frac{\beta^{\xi}}{\Gamma(\xi)} x^{\xi-1} e^{-\beta x} d x=1
$$

Fungsi karakteristik dari peubah acak $X$ berdistribusi $\operatorname{Gamma}(\xi, \beta)$ adalah

$$
\varphi_{X}(u)=\left(\frac{\beta}{\beta-i u}\right)^{\xi} .
$$

Karena

$$
\varphi_{n}(u)=\left[\varphi_{X}(u)\right]^{\frac{1}{n}},
$$

maka jelas bahwa $\varphi_{n}(u)$ merupakan fungsi karakteristik dari Gamma $\left(\frac{\xi}{n}, \beta\right)$. Jadi, distribusi Gamma merupakan distribusi terbagi tak hingga

$$
\left(\varphi_{n}(u) \sim \operatorname{Gamma}\left(\frac{\xi}{n}, \beta\right)\right) .
$$

Bentuk kanonik dari fungsi karakteristik terbagi takhingga berdistribusi Gamma, seperti dijelaskan oleh Lukacs (1970), dikarakterisasi oleh $\left(\gamma, \sigma^{2}, M\right)$, dan diberikan sebagai berikut:

$\varphi_{X}(u)=\exp \left[i u\left(\xi \int_{0}^{\infty} \frac{e^{-\beta x}}{1+x^{2}} d x\right)+\int_{+0}^{\infty}\left(e^{i u x}-1-\frac{i u x}{1+x^{2}}\right) d\left(-\xi \int_{x}^{\infty} \frac{e^{-\beta y}}{y} d y\right)\right]$,

di mana

$$
\gamma=\xi \int_{0}^{\infty} \frac{e^{-\beta x}}{1+x^{2}} d x, \sigma^{2}=0, \quad \operatorname{dan} M(x)=-\xi \int_{x}^{\infty} \frac{e^{-\beta y}}{y} d y, \quad x>0 .
$$

Selanjutnya akan dikaji fungsi distribusi dari peubah acak $Y=\alpha \log X$ (untuk selanjutnya $Y$ disebut peubah acak berdistribusi Log-Gamma), dimana $X$ adalah peubah acak berdistribusi Gamma, $\alpha \neq 0$, fungsi karakteristik dan bentuk kanonik dari fungsi karakteristiknya. Pandang dua kasus berikut. 
Kasus 1. Misalkan $\alpha$ adalah konstanta positif. Fungsi distribusi kumulatif dari peubah acak $Y$ adalah

$$
P\{Y \leq y\}=\frac{\beta^{\xi}}{\Gamma(\xi)} \int_{-\infty}^{y}\left[e^{\frac{\xi}{\alpha} t-\beta e^{\frac{t}{\alpha}}}\right] \frac{d t}{\alpha} .
$$

Kasus 2. Misalkan $\alpha$ adalah konstanta negatif $\left(\alpha^{\prime}=-\alpha\right)$. Fungsi distribusi kumulatif dari peubah acak $Y$ adalah

$$
P\{Y \leq y\}=1+\frac{\beta^{\xi}}{\Gamma(\xi)} \int_{y}^{\infty}\left[e^{\frac{\xi}{\alpha} t}\right]\left[e^{-\beta e^{t / \alpha}}\right] \frac{d t}{\alpha} .
$$

Fungsi karakteristik dari distribusi Log-Gamma dengan $\alpha$ positif maupun $\alpha$ negatif adalah

$$
E\left[e^{i u Y}\right]=\int_{-\infty}^{\infty} e^{i u y} f(y) d y
$$

Dengan memisalkan $e^{y / \alpha}=x$ untuk $\alpha$ positif dan $e^{-y / \alpha^{\prime}}=x$ untuk $\alpha$ negatif, maka diperoleh

$$
E\left[e^{i u Y}\right]=\frac{\Gamma(\xi+i \alpha u)}{\Gamma(\xi) \beta^{i \alpha u}}
$$

Diperoleh fungsi karakteristik dari distribusi Log-Gamma sebagai berikut.

$$
\varphi_{Y}(u)=\frac{\Gamma(i \alpha u+\xi)}{\Gamma(\xi) \beta^{i \alpha u}} .
$$

Selanjutnya, diberikan suatu teorema tentang fungsi karakteristik dari distribusi Log-Gamma.

Teorema 2.2. [1] Misalkan terdapat peubah acak $Y=\alpha \log X$, di mana $X$ adalah peubah acak berdistribusi Gamma dan $\alpha \in \mathbb{R}$, maka fungsi karakteristik dari fungsi distribusi $P\{Y \leq y\}$ dapat ditulis sebagai berikut

$$
\begin{aligned}
\frac{\Gamma(\xi+i \alpha u)}{\Gamma(\xi) \beta^{i \alpha u}}= & \exp \left[i u\left\{\alpha \frac{\Gamma^{\prime}(\xi)}{\Gamma(\xi)}-\alpha \log \beta+\alpha^{3} \int_{-\infty}^{-0} \frac{y^{2}}{1+\alpha^{2} y^{2}} \frac{e^{\xi y}}{\left(1-e^{y}\right)} d y\right\}\right. \\
& \left.+\int_{-\infty}^{-0}\left(e^{i u y}-1-\frac{i u y}{1+y^{2}}\right) \frac{e^{(\xi / \alpha) y}}{\left(1-e^{y / \alpha}\right)|y|} d y\right]
\end{aligned}
$$

dengan

$$
\begin{aligned}
\gamma & =\alpha \frac{\Gamma^{\prime}(\xi)}{\Gamma(\xi)}-\alpha \log \beta+\alpha^{3} \int_{-\infty}^{-0} \frac{y^{2}}{1+\alpha^{2} y^{2}} \frac{e^{\xi y}}{\left(1-e^{y}\right)} d y, \\
\sigma^{2} & =0 \\
M(y) & =\int_{-\infty}^{y} \frac{e^{(\xi / \alpha) s}}{\left(1-e^{s / \alpha}\right)|s|} d s, y<0 .
\end{aligned}
$$




\section{Aplikasi pada Pembuktian Rumus Perkalian Gauss dan Rumus Legendre}

Dalam subbab ini akan dijelaskan bahwa sifat ukuran Levy dapat digunakan untuk membuktikan rumus perkalian Gauss dan rumus Legendre.

Adapun bentuk rumus perkalian Gauss adalah sebagai berikut

$$
\Pi_{k=0}^{m-1} \Gamma\left(z+\frac{k}{m}\right)=m^{1 / 2-m z}(2 \pi)^{1 / 2(m-1)} \Gamma(m z) .
$$

Sedangkan rumus Legendre adalah sebagai berikut

$$
\Gamma(z) \Gamma\left(z+\frac{1}{2}\right)=2^{1-2 z} \sqrt{\pi} \Gamma(2 z),
$$

dengan $\alpha=1, z=\xi+i \eta$ dan $m=2,3, \cdots$.

Akan ditunjukkan bahwa rumus perkalian Gauss dapat dibuktikan dengan menggunakan sifat ukuran Levy dengan memisalkan $\alpha=1, z=\xi+i \eta$ dan $m=2,3, \cdots$.

Perhatikan bahwa ruas kiri dari rumus perkalian Gauss dapat ditulis sebagai berikut.

$$
\begin{aligned}
& \Pi_{k=0}^{m-1} \Gamma\left(z+\frac{k}{m}\right)=\Pi_{k=0}^{m-1} \Gamma\left(\xi+i \eta+\frac{k}{m}\right) \\
& =\Gamma(\xi) \beta^{i \eta} \Gamma\left(\xi+\frac{1}{m}\right) \beta^{i \eta} \ldots \Gamma\left(\xi+\frac{m-1}{m}\right) \beta^{i \eta} \\
& \exp \left[i \eta\left\{\frac{\Gamma^{\prime}(\xi)}{\Gamma(\xi)}-\log \beta+\int_{-\infty}^{-0} \frac{y^{2}}{1+y^{2}} \frac{e^{\xi y}}{\left(1-e^{y}\right)} d y\right\}\right. \\
& \left.+\int_{-\infty}^{-0}\left(e^{i \eta y}-1-\frac{i \eta y}{1+y^{2}}\right) \frac{e^{\xi y}}{\left(1-e^{y}\right)|y|} d y\right] \\
& \exp \left[i \eta\left\{\frac{\Gamma^{\prime}(\xi+1 / m)}{\Gamma(\xi+1 / m)}-\log \beta+\int_{-\infty}^{-0} \frac{y^{2}}{1+y^{2}} \frac{e^{(\xi+1 / m) y}}{\left(1-e^{y}\right)} d y\right\}\right. \\
& \left.+\int_{-\infty}^{-0}\left(e^{i \eta y}-1-\frac{i \eta y}{1+y^{2}}\right) \frac{e^{(\xi+1 / m) y}}{\left(1-e^{y}\right)|y|} d y\right] \\
& \cdots \exp \left[i \eta\left\{\frac{\Gamma^{\prime}(\xi+(m-1) / m)}{\Gamma(\xi+(m-1) / m)}-\log \beta+\int_{-\infty}^{-0} \frac{y^{2}}{1+y^{2}} \frac{e^{(\xi+(m-1) / m) y}}{\left(1-e^{y}\right)} d y\right\}\right. \\
& \left.+\int_{-\infty}^{-0}\left(e^{i \eta y}-1-\frac{i \eta y}{1+y^{2}}\right) \frac{e^{(\xi+(m-1) / m) y}}{\left(1-e^{y}\right)|y|} d y\right] \\
& =\Gamma(\xi) \Gamma\left(\xi+\frac{1}{m}\right) \cdots \Gamma\left(\xi+\frac{m-1}{m}\right) \beta^{i m \eta} \\
& \exp \left[i \eta\left\{\frac{\Gamma^{\prime}(\xi)}{\Gamma(\xi)}+\frac{\Gamma^{\prime}(\xi+1 / m)}{\Gamma(\xi+1 / m)}+\cdots+\frac{\Gamma^{\prime}(\xi+(m-1) / m)}{\Gamma(\xi+(m-1) / m)}\right\}\right. \\
& -i \eta m \log \beta+i \eta \int_{-\infty}^{-0} \frac{y^{2}}{1+y^{2}} \frac{e^{\xi y}}{\left(1-e^{y / m}\right)} d y \\
& \left.+\int_{-\infty}^{-0}\left(e^{i \eta y}-1-\frac{i \eta y}{1+y^{2}}\right) \frac{e^{\xi y}}{\left(1-e^{y / m}\right)|y|} d y\right] .
\end{aligned}
$$


Selanjutnya dengan mengganti variabel $y$ dengan $m y$, diperoleh

$$
\begin{aligned}
\Pi_{k=0}^{m-1} \Gamma\left(\xi+i \eta+\frac{k}{m}\right)= & \Gamma(\xi) \Gamma\left(\xi+\frac{1}{m}\right) \cdots \Gamma\left(\xi+\frac{m-1}{m}\right) \beta^{i m \eta} \\
& \exp \left[i \eta\left\{\frac{\Gamma^{\prime}(\xi)}{\Gamma(\xi)}+\frac{\Gamma^{\prime}(\xi+1 / m)}{\Gamma(\xi+1 / m)}+\cdots+\frac{\Gamma^{\prime}(\xi+(m-1) / m)}{\Gamma(\xi+(m-1) / m)}\right\}\right. \\
& -i \eta m \log \beta+i m \eta \int_{-\infty}^{-0} \frac{y^{2}}{1+y^{2}} \frac{e^{m \xi y}}{\left(1-e^{y}\right)} d y \\
& \left.+\int_{-\infty}^{-0}\left(e^{i m \eta y}-1-\frac{i m \eta y}{1+y^{2}}\right) \frac{e^{m \xi y}}{\left(1-e^{y}\right)|y|} d y\right] .
\end{aligned}
$$

Karena

$$
\begin{aligned}
& \frac{m \Gamma^{\prime}(m \xi)}{\Gamma(m \xi)}-\left\{\frac{\Gamma^{\prime}(\xi)}{\Gamma(\xi)}+\frac{\Gamma^{\prime}(\xi+1 / m)}{\Gamma(\xi+1 / m)}+\cdots+\frac{\Gamma^{\prime}(\xi+(m-1) / m)}{\Gamma(\xi+(m-1) / m)}\right\} \\
= & m \int_{+0}^{\infty} \frac{e^{-t}-e^{-m t}}{t} d t=m \log m,
\end{aligned}
$$

dan

$$
\begin{aligned}
\frac{\Gamma(\xi) \Gamma(\xi+1 / m) \cdots \Gamma(\xi+(m-1) / m)}{\Gamma(m \xi)} & =\frac{\Gamma(1 / m) \Gamma(2 / m) \cdots \Gamma((m-1) / m)}{m^{m \xi-1}} \\
& =(2 \pi)^{(m-1) / 2} m^{1 / 2-m \xi},
\end{aligned}
$$

maka diperoleh

$$
\begin{aligned}
\Pi_{k=0}^{m-1} \Gamma\left(\xi+i \eta+\frac{k}{m}\right)= & (2 \pi)^{(m-1) / 2} m^{1 / 2-m(\xi+i \eta)} \Gamma(m \xi) \beta^{i m \eta} \\
& \exp \left[i m \eta\left\{\frac{\Gamma^{\prime}(m \xi)}{\Gamma(m \xi)}-\log \beta+\int_{-\infty}^{-0} \frac{y^{2}}{1+y^{2}} \frac{e^{m \xi y}}{\left(1-e^{y}\right)} d y\right\}\right. \\
& \left.+\int_{-\infty}^{-0}\left(e^{i m \eta y}-1-\frac{i m \eta y}{1+y^{2}}\right) \frac{e^{m \xi y}}{\left(1-e^{y}\right)|y|} d y\right] \\
= & (2 \pi)^{(m-1) / 2} m^{1 / 2-m(\xi+i \eta)} \Gamma(m(\xi+i \eta))
\end{aligned}
$$

untuk $\xi>0$.

Berdasarkan uraian di atas, maka diperoleh

$$
\Pi_{k=0}^{m-1} \Gamma\left(z+\frac{k}{m}\right)=m^{1 / 2-m z}(2 \pi)^{1 / 2(m-1)} \Gamma(m z) .
$$

Hal tersebut menunjukkan bahwa rumus perkalian Gauss dapat dibuktikan dengan menggunakan sifat ukuran Levy, yaitu dengan memisalkan $\alpha=1, z=\xi+i \eta$ dan $m=2,3, \cdots$. Sedangkan jika diganti $m=2$, maka diperoleh rumus Legendre sebagai berikut.

$$
\Gamma(z) \Gamma\left(z+\frac{1}{2}\right)=2^{1-2 z} \sqrt{\pi} \Gamma(2 z)
$$




\section{Ucapan Terima kasih}

Penulis mengucapkan terima kasih kepada Bapak Dr. Dodi Devianto, M.Sc, Bapak Dr. Admi Nazra, Bapak Dr. Muhafzan, Ibu Dr. Maiyastri, Ibu Dr. Lyra Yulianti dan Bapak Dr. Mahdhivan Syafwan yang telah memberikan masukan dan saran sehingga paper ini dapat diselesaikan dengan baik.

\section{Daftar Pustaka}

[1] Katsuo, T. 2008. A Note on Gamma Functions. Japan Mathematical Research. Vol 1579 : 110-118.

[2] Laha, R. G. dan V. K. Rohatgi. 1979. Probability Theory. John Wiley \& Sons, New York.

[3] Lukacs, E. 1970. Characteristic Function. Second Edition. Griffin, London. 